\title{
Estratificações urbanas: Preexistências e projeto contemporâneo entre conhecimento e uso
}

\author{
Alessandro Massarente
}

Professor do Departamento de Arquitetura da Universidade de Ferrara (UNIFE), Itália

Contato: alessandro.massarente@unife.it

Tradução:

Luyza De Luca

Aluna do Departamento de Arquitetura e Urbanismo da PUC-Rio e da Universidade de Bolonha (UNIBO), Itália

Contato: luyzadeluca@uol.com.br

Revisão técnica:

Ana Paula Polizzo

Professora do Departamento de Arquitetura e Urbanismo da PUC-Rio e do Departamento de História e Teoria da Faculdade de Arquitetura e Urbanismo da Universidade Federal do Rio de Janeiro (FAU-UFRJ)

Contato: polizzo@fau.ufrj.br

\section{RESUMO}

Numerosos projetos na história da arquitetura modificaram os usos de edifícios preexistentes nos quais é possível reconhecer uma identidade formal clara: frequentemente, nesses casos, a intervenção de transformação contribuiu não apenas para manter a construçáo viva, mas também, para fortalecer sua unidade figurativa e seu papel na cidade.

Confrontado com uma "tradição moderna", composta por edifícios e projetos, mas também com um horizonte amplo e variado de textos, escritos e artigos que exploraram esta vertente da arquitetura e que caracterizou uma importante fase da arquitetura italiana do século XX, o projeto contemporâneo nas preexistências históricas é cada vez mais claramente definido como uma forma que o arquiteto tem de explorar sua relaçáo com o presente, através de algumas estratégias possíveis.

Palavras-chave: Estratificação urbana, projeto de conhecimento, projeto de uso.

\section{ABSTRACT}

Numerous projects in the history of architecture have modified the uses of preexisting buildings in which a clear formal identity can be recognized: often in these cases the transformation intervention has contributed not only to keeping the building alive but also to strengthening its figurative unity and its role in the city. Confronted with a "modern tradition", composed of buildings and projects, but also with a wide and varied horizon of texts, writings and articles that explored this line of architecture and which characterized an important phase of 20th century Italian architecture, contemporary design in historical pre-existences is increasingly clearly defined as a way for the architect to explore his relation to the present through some possible strategies.

Key-words: Urban stratification, knowledge design, use design. 
No contexto do debate nacional e internacional relativo às metodologias de valorização dos bens arquitetônicos e culturais, a realização de estudos sobre a cidade - desenvolvidos especialmente na Itália - representou uma importante referência constituindo, na virada dos anos 1950 e 1960, um campo de indagaçóes privilegiado por disciplinas como projeto de arquitetura, planejamento urbano e história da arquitetura.

\section{Transformaçóes urbanas e mutaçóes de uso}

Objetos de investigação dentro desse campo foram, por exemplo, os processos de desativação funcional das áreas marginais da cidade, em geral formadas por complexos industriais a procura de uma nova função, as áreas abandonadas dentro dos sistemas portuário e ferroviário produzidos por uma nova lógica de disposição dos sistemas infra estruturais, os fenômenos de terciarização nos centros urbanos onde se produziu a substituição dos bens manufaturados ou a sua modificação funcional, mas também a coexistência de traços do antigo e de consideráveis fragmentos da arquitetura moderna no coração da cidade contemporânea.

Muitas dessas questôes são abordadas em um livro (FRANCO et al., 2002) que reúne as contribuiçôes trazidas de diversos relatores para uma conferência internacional chamada "Dinâmicas de transformação da cidade. Métodos e políticas de valorização dos bens arquitetônicos e ambientais" ${ }^{1}$ durante a qual tentou-se identificar alguns fenômenos de

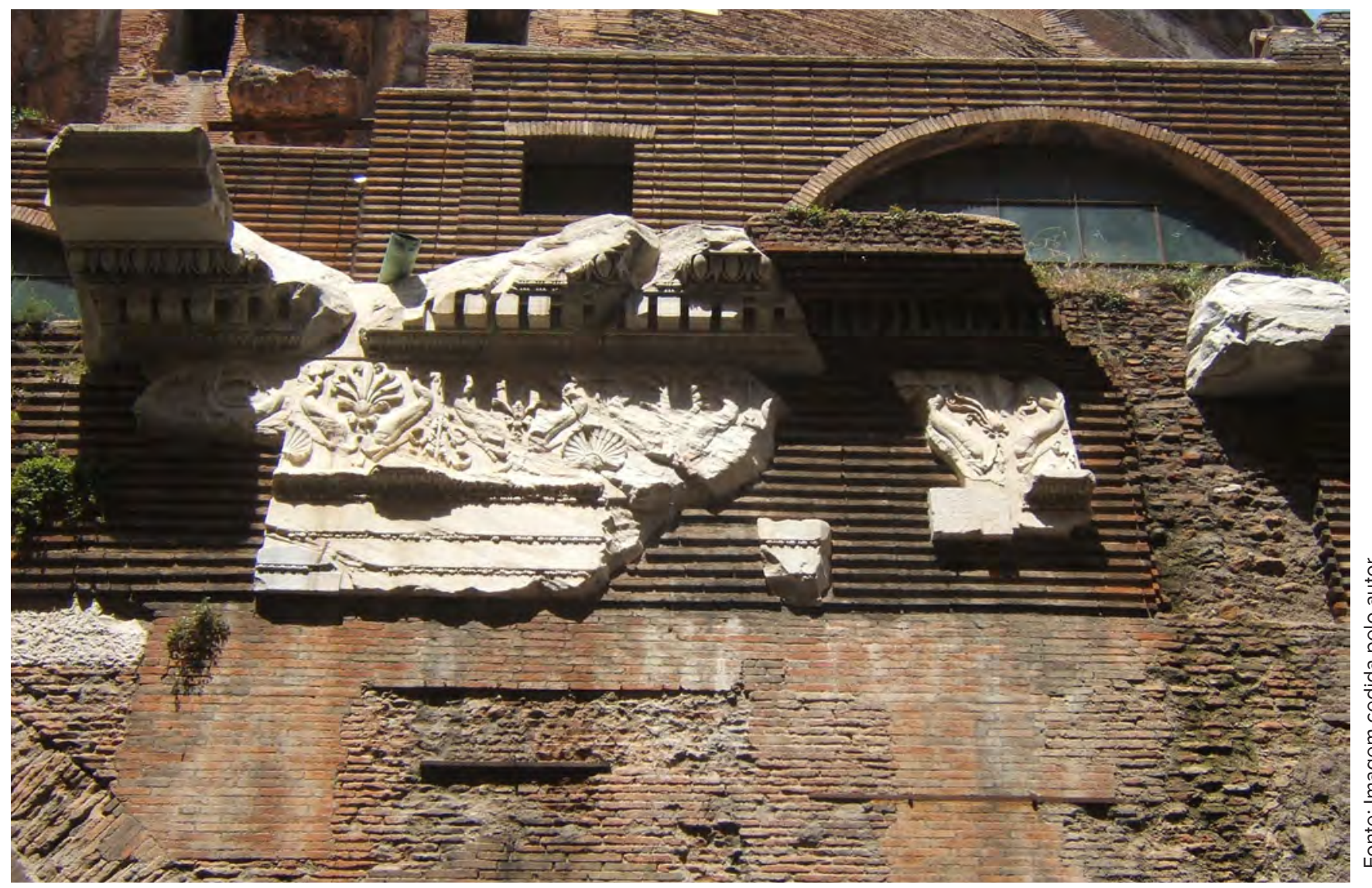

Figura 1: Roma, Panteão, fachada lateral com diferentes fragmentos e superfícies de alvenaria.

Revista online do Departamento de Arquitetura e Urbanismo da Pontifícia Universidade Católica -

Puc-Rio - Rio de Janeiro Brasil

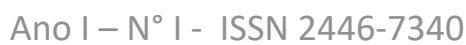


transformação da cidade antiga através de um ponto de vista particular: a relação entre formas e modos de uso na arquitetura ${ }^{2}$.

Com esse livro pretendeu-se despertar a atenção do debate contemporâneo para a requalificação de complexos arquitetônicos que puderam atuar enquanto catalizadores urbanos, através dos quais fosse possível interpretar a identidade do pretenso tecido urbano, definindo novos modos de uso e novas configuraçôes que fossem capazes de reavivar partes desse tecido.

Alguns dos casos ilustrados nesse livro levantaram ao menos duas importantes questôes as quais considero ser, ainda hoje, passíveis de reflexão. (SECCHI, 1999, p.22-24).

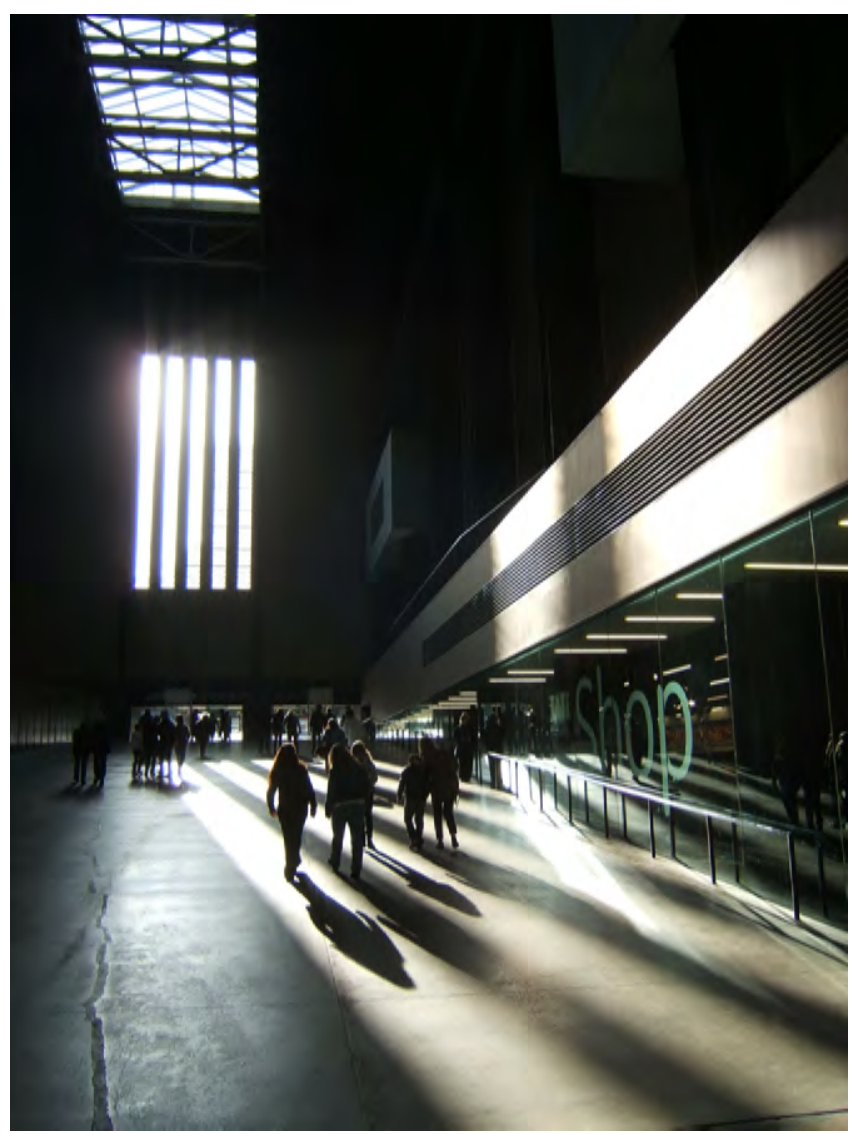

A primeira questão reside na possibilidade de relacionar, através dessas experiências de recuperação dos centros antigos, duas diferentes práticas: a prática da planificação e dos estudos sobre a cidade com a prática do projeto urbano, experimentada nas últimas décadas do século XX em cidades europeias como Barcelona, Paris, Berlim e Londres.

A segunda questão consiste na tentativa de definir políticas e metodologias de requalificação da cidade que possam contornar as restriçóes impostas por uma radicalização da cultura de conservação, que muitas vezes tende a impor resistência a uma compreensão mais atenta das características tanto da cidade antiga quanto da contemporânea, bem como as suas potencialidades em termos de transformaçáo e requalificação.

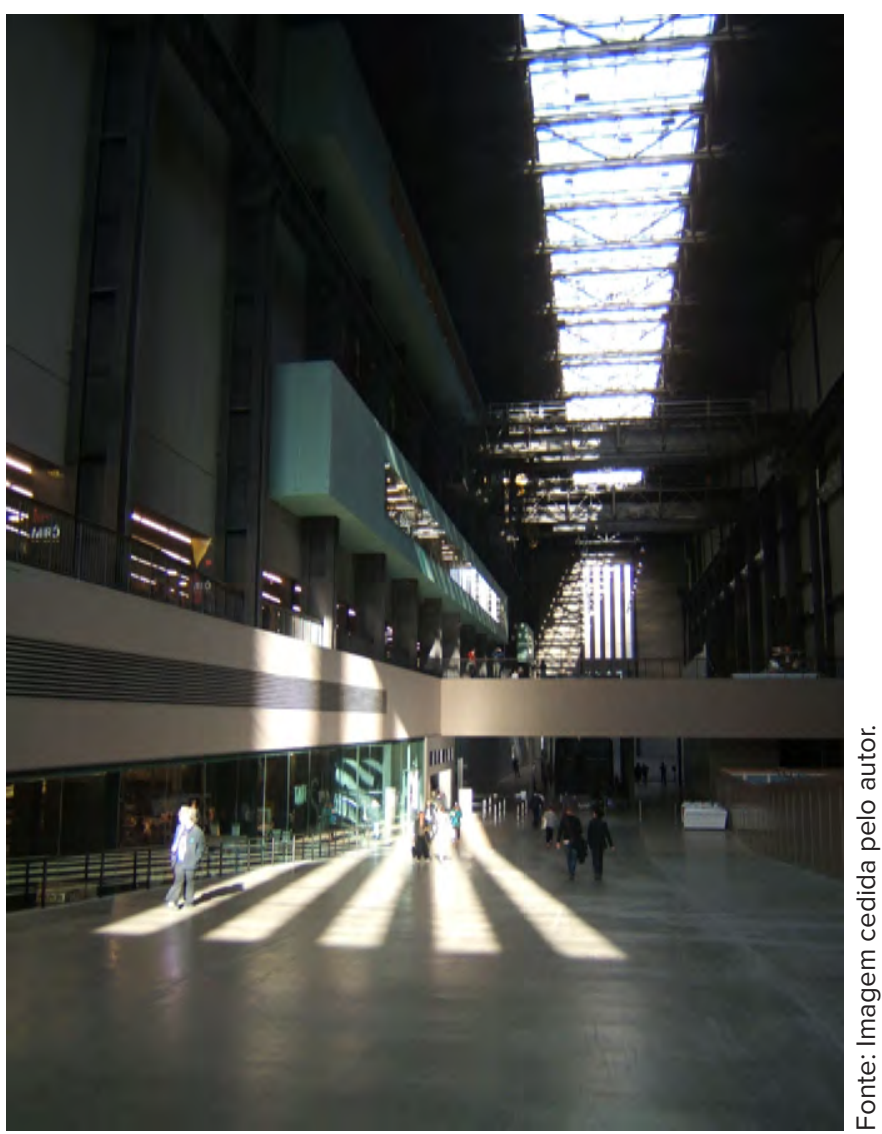

Figuras 2 e 3: Londres, Bankside, Tate Modern, Tate Gallery of Modern Art, Herzog \& De Meuron, 1994-2000. 


\section{Questóes de método}

$\mathrm{Na}$ Itália, há muito que se nota o considerável peso que a radicalizaçáo da cultura da conservação exerceu no âmbito do patrimônio, com todas as consequências que acarreta para o projeto de arquitetura, que frequentemente acaba marcado pelos equívocos produzidos por um desejo de conservaçáo integral do próprio patrimônio e pela irremediável perda daquilo que ocasionalmente é considerado não digno de atenção e proteção. Como, por exemplo, edifícios do século XX que constituem parte integrante de alguns fragmentos da cidade ou, alguns complexos industriais ou edifícios relacionados à cultura material, que por vezes não são protegidos ou, no pior dos casos, são objetos de intervenção difíceis de defender.

O valor histórico (RIEGL, 1903, p.48-49) que fundamenta a declaração de tutela dos bens, predominantemente ligado à sua condição de antiguidade, é evidentemente insuficiente para fins de sua proteção, mas é usado como argumento desde que seja necessário requalificar e valorizar esses mesmos bens para dar a eles um significado e um novo sentido na cidade.

Neste contexto, a relação entre a cidade histórica e arquitetura contemporânea pode representar o campo de investigação para explorar a atualidade e o valor epistemológico de algumas teorias arquitetônicas e das técnicas projetuais correlatas.

Um desses valores (GABETTI, 1983a, p.78) é representado, por exemplo, pelo fundamento tipológico de algumas metodologias de projeto. Esses valores, no entanto, são comumente desvirtuados e considerados como uma mera interpretação evolutiva dos tipos, tendendo muitas vezes a permanecer no estágio de simples conscientização da presença de algumas permanências históricas na cidade contemporânea.

À luz de alguns estudos sobre o território, parece evidente que o conceito de tipo apareça, cada vez menos, como referência a edifícios que podem ser adequados a um modo de uso unívoco e caracterizado. Nas paisagens onde se evidencia o fenômeno do espraiamento urbano, como em alguns lugares da cidade contemporânea, são cada vez mais recorrentes os casos em que um único edifício sintetiza em si mesmo uma tal complexidade de formas de uso que dificulta, ou mesmo torna improvável, sua esquematização tipológica. É o caso de grandes equipamentos públicos, relacionados de forma complexa ao contexto ao que pertencem, nos quais modos de uso de natureza radicalmente distintas convivem em um mesmo lugar: por exemplo, na arquitetura Bigness ${ }^{3}$ (KOOLHAAS, 1995a), nas grandes infraestruturas para a mobilidade, nos centros comerciais, nos complexos de serviços, nos parques tecnológicos.

Diante desses fenômenos, parece difícil recorrer à aplicação de métodos globais de análise dos modos de uso capazes de fornecer instrumentos de leitura e intervenção, mas também parece impraticável uma esquematização da relação que as mesmas formas de uso têm com a configuração do edifício através do conceito de tipo.

Sem considerar, por um lado, o centro histórico como o único "núcleo de valor e sentido, fonte de todo significado" e sem deixar-se levar, por outro lado, pela Cidade Genérica, em direção a uma "cidade sem história" (KOOLHAAS, 1995b, p.3031), se poderia experimentar, com maior intensidade e propósitos de confiabilidade e verificação científica, 
uma ideia de cidade que não é somente legível enquanto uma grande obra arquitetônica, mas que é também transformável por discretos pontos - no antigo sentido de discretum $^{4}$-, ou ainda, bem visíveis, distintos, discordantes, relendo uma tradição que, através da Veneza de Palladio, da Londres de Wren e da Berlim de Schinkel, vem transfigurando a cidade contemporânea.

Nesta perspectiva, os vazios urbanos assumem um papel cognitivo e instrumental que vai além das experiências de requalificação realizadas ao longo dos últimos 30 anos nas principais capitais europeias como no caso do IBA $\mathrm{IB}^{5}$ em Berlim, onde importantes experimentaçôes foram conduzidas durante seu desenvolvimento.

\section{Uma tradição moderna na Itália}

Há vários projetos na história da arquitetura italiana moderna e contemporânea que, ainda que, modificando os usos dos edifícios históricos preexistentes nos quais é ainda possível reconhecer uma identidade formal clara, frequentemente a intervenção de transformação contribuiu não apenas para manter vivo o edifício, mas também para reforçar a sua unidade figurativa e seu papel na cidade.

Assim ocorreu, por exemplo, no Convento de Sant'Ambrogio do século XV em Miláo, que se tornou sede da Universidade Católica, seguindo um plano de obras realizado por Giovanni Muzio entre 1921 e 1949; ou, em outros casos, como a Villa Muggia em Imola por Piero Bottoni (1936-1938), a Villa Mantelli em Sestri Levante por Luigi Carlo Daneri (1938-40), as Terme Della Regina Isabella em Ischia por Ignazio Gardella (1950-53), o Museo di Palazzo Rosso em Genova por Franco Albini
(1952-61), o Museo di Palazzo Abatellis em Palermo por Carlo Scarpa (1953-54); ou os projetos para a Casa Vietti em Cortesella de Giuseppe Terragni (1940-41), para o Sacrario nel Mausoleo di Augusto em Roma por Adalberto Libera (1936); ou mesmo as transformaçóes funcionais de edifícios existentes nos projetos de Aldo Rossi, Giancarlo De Carlo, Luciano Semerani, Vittorio Gregotti, Roberto Gabetti e Aimaro Isola, Giorgio Grassi, Francesco Venezia, Renzo Piano, para citar alguns.

Esses edifícios e projetos, e mais uma ampla e variada gama de textos, ensaios e artigos surgem em diversas ocasiôes, elaborados por diferentes autores também muito distantes entre si - de Gustavo Giovannoni (1873-1947) ao próprio Giovanni Muzio (18931982), que se dedica ao planejamento urbano; de Piero Bottoni (1903-1973) com seu olhar mutável em direçáo à cidade antiga a Ernesto Nathan Rogers (1909-1969) e seu debate sobre as preexistências ambientais; de Roberto Pane (1897-1987) a Costantino Dardi (1936-1991) - e parecem traçar o perfil de uma tradiçáo italiana profundamente enraizada no panorama arquitetônico do século XX. Porém estes, na realidade, são fruto do extraordinário efeito de uma atenção em direção ao patrimônio histórico que a cultura arquitetônica sempre demonstrou, especialmente na Itália a partir do Renascimento (DE FUSCO, 1999, p.18-24).

Portanto, não é por acaso que expoentes dessa que Edoardo Persico chamava de "tradição moderna", sejam membros do Gruppo $7^{6}$, que em seus primeiros artigos em fins dos anos 1920 , escreveram sobre "uma nova era arcaica" (MASSARENTE, 2016), utilizando a arquitetura antiga como um ponto de vista privilegiado para a definição de poéticas para a implementação de instrumentos projetuais contemporâneas 

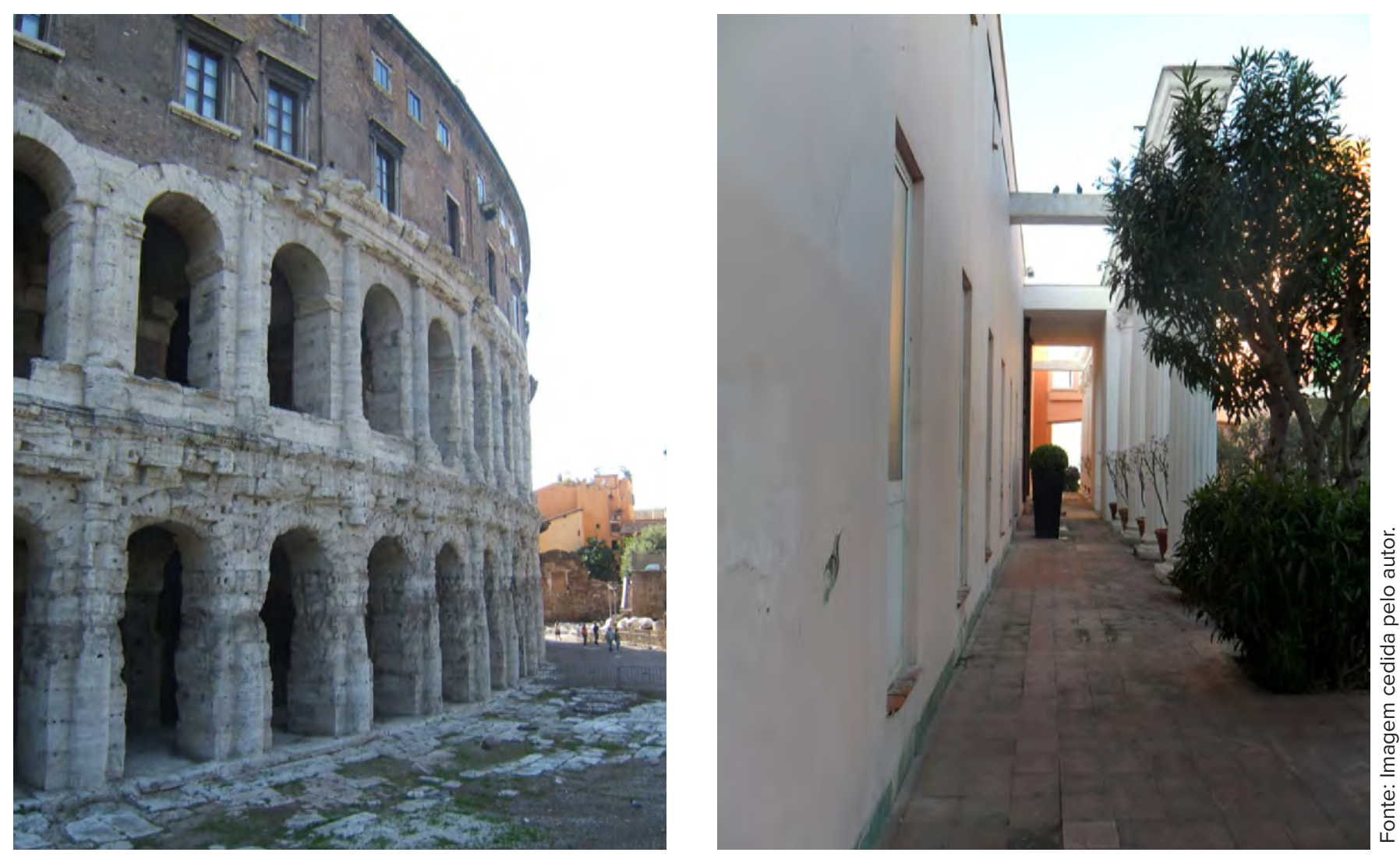

Figuras 4 e 5: Á esquerda, Palazzo Savelli sobre o Teatro di Marcello, em Roma por Baldassarre Peruzzi (15231529) e, à direita, Terme della Regina Isabella em Lacco Ameno, Ischia, por Ignazio Gardella, (1950-53).

(BORSI, ROGGERO, 1967, p.12-13).

Exemplos dessa capacidade de leitura figurativa e formal do antigo figuram nas obras e escritos de arquitetos desde o Renascimento até os dias de hoje, como por exemplo, Michelangelo, Palladio, Giovanni Battista Piranesi, Johann Bernhard Fischer von Erlach, John Soane, Auguste Perret e Louis I. Kahn. Estes souberam ler no edifício em estado de ruina o seu espírito original e a sua estrutura configurativa, com uma intensidade equivalente àquela como quando o edifício estivesse em construção, com suas formas em devir. Assim, mostraram em seus próprios projetos essa particular habilidade de leitura figurativa de edifícios históricos, através da qual foi possível pôr em evidência as "condições permanentes" da arquitetura: "A grande arquitetura é aquela que produz belas ruínas" (PERRET, 1929, p.230), como afirma o conhecido aforismo de Auguste Perret.

Para além da arquitetura, inclusive no sistema mais amplo das artes, a dissolução de uma obra é lida como um campo de revelação de seus princípios geradores, identificando na destruição de uma obra prima a noçâo viva e ativa da técnica. Ocupandose das formas na matéria, Henri Focillon escreve sobre as estruturas frágeis presentes nas gravuras de Rembrant, cujas impressões repetidas se tornam progressivamente mais fracas, mas não obstante reveladoras de procedimentos composicionais, numa espécie de "genealogia reversa" da obra (FOCILLON, 1943, p.66-67).

À luz de tais experimentos conduzidos, não apenas Revista online do Departamento de Arquitetura e Urbanismo da Pontifícia Universidade Católica - 
na Itália, sobre o tema das transformaçóes no uso de edifícios do passado, o projeto contemporâneo em preexistências históricas é cada vez mais claramente definido como um modo que o arquiteto tem de explorar a própria relação com o presente, de conhecê-lo a tal ponto de transformá-lo, com as mais diversas inflexôes linguísticas, que vão, por exemplo, desde o processo de simplificação e "redução dos elementos da arquitetura, como procedimento técnico" (GRASSI, 1999, p.34-35), à contraposição entre o antigo e o contemporâneo; da contaminaçáo entre antigas e novas linguagens, a uma vasta pesquisa eclética tendo em vista uma maior complexidade (MASSARENTE, 1997, p.86-91).

Essas diferentes inflexóes da arquitetura contemporânea em relação às preexistências são frequentemente reduzidas - não apenas pelo jornalismo descuidado, mas também pelos atentos estudiosos - a algumas frases de efeito vazias, como o suposto "rompimento com o passado" promovido pelo Movimento Moderno, ou ainda o "come era dove era", que quase nunca se mostra compatível com as cidades que são verdadeiras estratificaçôes urbanas.

\section{De uma tradiçáo moderna a diferentes posiçóes em relaçáo a preexistências}

Para além das palavras de efeito, há aqueles que reafirmam a centralidade do papel urbano do monumento, a ponto de justificar o modo, por vezes controverso, pelo qual ele é restaurado. É a teoria do caso a caso $^{8}$ (ANNONI, 1946), cujo mérito é esclarecer, mais uma vez que, aquele que restaura, reconstrói ou recompõe deve ser não um técnico superespecializado, mas, acima de tudo, um arquiteto capaz de interpretar com seus próprios instrumentos o texto antigo. Por outro lado - ainda que, na mesma posiçáo dos defensores do caso a caso - existem aqueles que sustentam a reavaliação do projeto de restauração entendido em termos tradicionais, se colocando de forma contrária aos teóricos da conservaçâo (que se limitam à exclusiva manutenção do patrimônio histórico).

Náo raro o projeto contemporâneo sobre as preexistências oscila entre diversas opçóes, por vezes relacionadas a diferentes formas de interpretar a relação entre o antigo e o novo: de um lado a vontade de tornar imperceptível a transformação recorrendo a uma "cópia" real; de outro, a tentativa de trabalhar no limite de um conceito de continuidade temporal que confunda aquilo que é antigo com aquilo que não é; e finalmente, a necessidade de mostrar claramente, por comparação, as inovaçóes e as permanências, amiúde reduzidas a fragmentos da unidade originária (BRANDOLINI, 1999, p.40-57).

O restauro urbano é citado por alguns como a disciplina capaz de regular e controlar as intervençóes dentro das cidades históricas. Mas há uma contradição implícita no ponto de vista de seus defensores, pois é precisamente o fato de diferenciar a cidade histórica das "outras" cidades - os vazios criados a partir de operaçóes descontinuadas, as margens residenciais fortemente degradadas, sistemas de assentamento dispersos no território -, e especialmente o perigoso hábito de entender a cidade histórica como um fato consumado e imutável, que desperta uma grande perplexidade, considerando-se que são justamente os espaços urbanos das cidades que mostram e representam estratificaçóes de diferentes períodos históricos. Reduzindo o problema a uma forma extremamente sintética, correndo o risco cair no esquematismo, o restauro urbano parece conduzir inexoravelmente à homologação, enquanto a estratificação presente nas cidades nos ensina a 
preservar a riqueza da diversidade.

Se observarmos este debate de um ponto de vista diametralmente oposto, não podemos deixar de considerar a ferramenta de substituição edilícia inteligente, que é uma prática consolidada em vários países, com a qual é possível, com as ferramentas de controle necessárias, definir novas formas de assentamentos e estruturas morfológicas na cidade histórica, sem apagar as identidades presentes.

Se na Itália o modelo ligado à recuperação dos centros históricos - como o caso de Bolonha representou uma das experiências mais avançadas do urbanismo italiano da segunda metade do século XX (CONFORTO, et al., 1977, p.362-363), o mesmo não se pode dizer das experiências de transformaçóes mais radicais de partes da cidade. Por exemplo, as mesmas modalidades de substituição edilícia e de transformaçôes radicais tem sido implementadas nos casos de intervençôes relativas a zonas industriais abandonadas, sem a atenção necessária para trechos de tecido urbano que teriam exigido métodos de intervenção mais orientados ao restauro ou transformaçóes mais atentas capazes de recuperar o valor de testemunho, adaptando os edifícios a novas formas de uso capazes de ativar novas dinâmicas de desenvolvimento local. Além disso, já na formação do conceito de proteção dos centros históricos, era necessário dedicar especial atenção ao território a fim de compreender mais profundamente a natureza do patrimônio histórico e a formação dos mesmos centros urbanos. $\mathrm{O}$ conceito de patrimônio tende a abranger um recorte sempre mais amplo e com maior variedade de objetos, bens e lugares, incluindo ainda a paisagem, e é precisamente por esse motivo que a proteção deste patrimônio deve conhecer filtros que permitam discernir a qualidade dos bens, sem cair, como frequentemente acontece, na afirmação da validade de cada testemunho, o que de fato leva à degradação social e econômica do mesmo bem (GABETTI, 1983a, p.74-75).

\section{Por um projeto de uso}

Uma das questóes que parece emergir é a inadequação do vocabulário e dos instrumentos utilizados pela cultura arquitetônica contemporânea, quando se aborda o problema da requalificação de edifícios históricos da cidade. Inadequação, por exemplo, do termo "reutilização", que permitiu extensōes arbitrárias e intervençôes radicais de transformação em preexistências históricas: um termo não só pobre de significados, mas também ambíguo, uma vez que tende a esconder as implicaçóes formais que são subjacentes às modificaçóes funcionais dos edifícios ao longo do tempo (GABETTI, 1983b, p.124-125).

Para testemunhar o interesse despertado por essas questôes, há uma ampla bibliografia sobre o assunto (FISCHER, 1994; ROBERT, 1990), que aborda particularmente o problema construtivo, técnicoeconômico e administrativo atrelado à transformação dos modos de uso em edifícios preexistentes. Parecem ausentes nesses textos, no entanto, recursos para uma leitura mais especificamente compositiva das transformaçóes das formas de uso na arquitetura: uma leitura que, sem cair na insolúvel dupla forma / função, vise à pesquisa de um primeiro e fascinante princípio, ainda que enganoso, e saiba definir a lógica figurativa e os processos ideacionais presentes no projeto e na construção de uma obra (GABERRI, 1983a, p.87).

Além da especificação das diferentes categorias de intervenção mencionadas acima - "conservação", "restauração", "reutilização", "substituição" - e de 
outras mais refinadas, como "conservação integrada" - conceito através do qual o patrimônio arquitetônico se configura como um componente essencial do processo de desenvolvimento econômico - os casos de transformação funcional de edifícios históricos abrem outras questôes de método de inegável importância.

Muitas vezes, no projeto de restauração ou reabilitação de edifícios históricos, além da reconstrução do estado original do edifício, há a consideração de "reverberaçôes de uso" concebíveis para as formas dos edifícios que permanecem ativas em um novo contexto "diferente daquele antigo para o qual foram configuradas" (DE CARLO, 1966, p.123124). Um conceito desenvolvido pela primeira vez por Giancarlo De Carlo e posteriormente retomado por Roberto Gabetti, que atualiza uma tradição palladiana - "o constante pensamento sobre o uso"10 de Daniele Barbaro - e iluminista, de Carlo Lodoli em diante (GABETTI, 1983a, p. 49) ${ }^{11}$.

Por outro lado, repetidamente testemunhamos o paradoxo de edifícios restaurados para os quais foram investidos muitos recursos, utilizando as melhores técnicas e as maiores atençôes filológicas sem que, paralelamente fosse desenvolvido por um arquiteto ou pelo adquirente um projeto de uso coerente com a vida e as atividades previstas para acontecer no interior do edifício. Um projeto de uso entendido como definição das exigências compatíveis com os dados do processo de conhecimento, do qual é investido o edifício objeto de restauro ou transformação. Um processo de estudo que contribui para a definiçáo dos valores do edifício, que não aponta para a acumulação de dados, mas vive da complexa relação entre história e projeto. Um projeto que seleciona, orienta e às vezes coloca em crise o diálogo entre os saberes que regem as práticas analíticas desenvolvidas no processo de conhecimento, como os diagnósticos químicos dos materiais, o estudo de estruturas, os levantamentos para o estudo da geometria do edifício, as análises das obras pictóricas e de decoraçóes, as pesquisas sobre a história da arte e história da arquitetura (PASTOR, 1989, p.10-11).

À luz das considerações acima, o processo de conhecimento que leva a transformar para preservar em vida um edifício mostra a necessidade de se afirmar a centralidade do significado no projeto arquitetônico. Tal significado pode ser lido na estratificação urbana dos modos de uso que ao longo do tempo caracterizaram um edifício e no entrelaçamento de interpretaçóes que se dão através da história e dos projetos de transformação e posterior ressignificação (MANIERI ELIA, 1990, p.46). Este significado - atribuído ao longo do tempo a um edifício ou a uma parte da cidade - parece expressar a mesma importância e a mesma ênfase que uma arquitetura e uma cidade exercem aos nossos olhos, quando pensamos na vida ou nas vidas que as atravessaram, nas sucessivas transformaçôes que as marcarão.

Como Focillon escreveu (FOCILLON, 1949, p.80), [...] a substância da arte é então a mesma vida. De maneira mais geral, o artista está diante da existência como Leonardo da Vinci diante do muro em ruínas, devastado pelo tempo e pelos invernos, crivado de disparos, manchado pelas águas da terra e do céu, permeado por rachaduras. Nós vemos apenas vestígios de circunstâncias ordinárias. $\mathrm{O}$ artista vê figuras de homens distintas ou amalgamadas, batalhas, paisagens, cidades que colapsam - formas. 


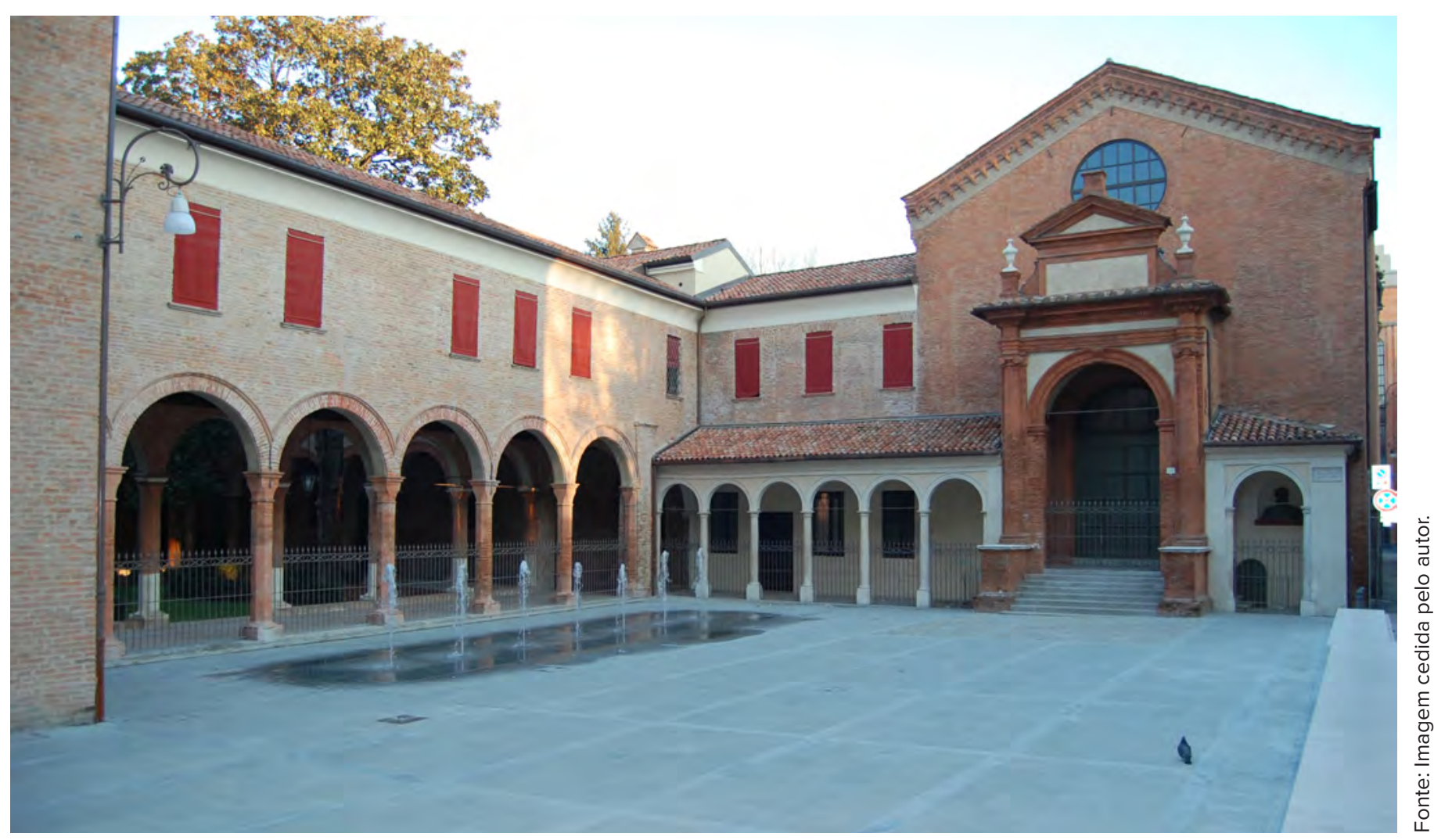

Figura 6: Ferrara, Auditório no complexo do antigo Hospital de Sant'Anna, fachada voltada para a Piazzetta Sant'Anna após o restauro.

\section{O caso do Auditório de Ferrara}

A sala de concertos e o complexo do antigo hospital de Sant'Anna, constituintes de um relevante marco do patrimônio histórico, arquitetônico e cultural da cidade de Ferrara foram objeto, nos anos passados, de uma pesquisa realizada por um grupo de docentes ${ }^{12}$ do Ateneo Ferrarese ${ }^{13}$ e posteriormente publicada em livro (MASSARENTE, 2012).

Entre 2006 e 2008, a pesquisa levou ao desenvolvimento da primeira campanha aprofundada de investigaçôes cognitivas (arquivísticas, históricas, materiais) e levantamentos (dos espaços, das estruturas, das instalaçôes, das técnicas e dos materiais de construtivos e decorativos) bem como a elaboração de um completo projeto de restauração de todo o complexo formado pela sala de concertos e pelos espaços internos e externos do atual Conservatório de Música Girolamo Frescobaldi.

A partir desta pesquisa, o histórico complexo arquitetônico do Arcispedale di Sant'Anna surge em sua estratificação secular, que a partir do final do século XIV com as primeiras ocupaçôes de implantaçôes conventuais se estabelece o novo complexo hospitalar na primeira metade do século $\mathrm{XV}$, posteriormente hospital para doentes mentais e feridos, dados os problemas de densidade e salubridade que seus espaços apresentavam, até a sua definitiva desativação em 1927.

Do final da década de 1920 e nos anos 1930, primeiro através dos planos urbanísticos de Ciro Contini e depois com os projetos em escala urbana

Revista online do Departamento de Arquitetura e Urbanismo da Pontifícia Universidade Católica -

Puc-Rio - Rio de Janeiro Brasil

Ano I - N ${ }^{\circ}$ I - ISSN 2446-7340 


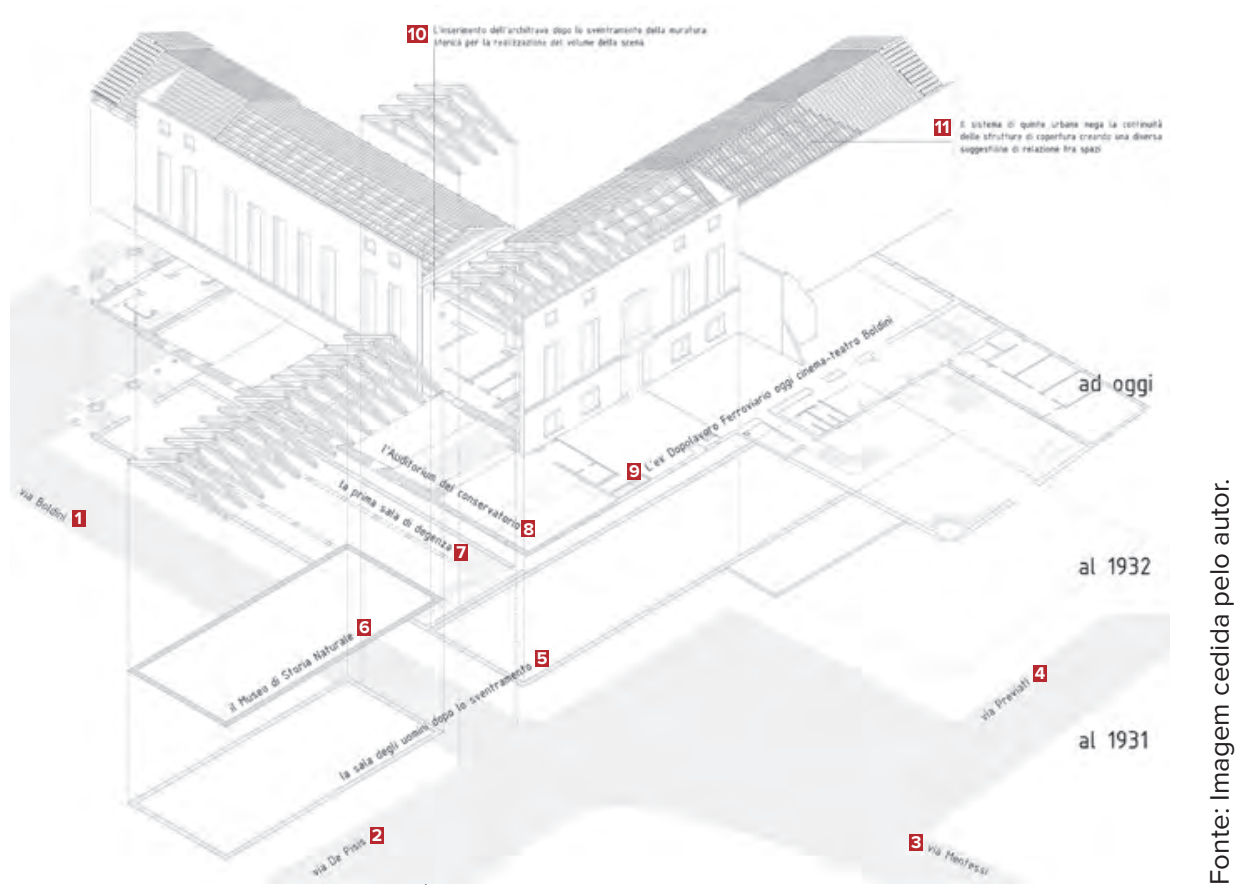

Figura 7: Ferrara, Auditório no complexo do antigo Hospital Sant'Anna. Esquema axonométrico com as principais transformaçôes da área, desde 1931 aos dias de hoje

1. Via Boldini / 2. Via de Pisis / 3. Via Mentessi /4. Via Previati / 5. A sala dos homens depois da demolição / 6. O Museu de História de Natural / 7. A primeira sala de hospitalização / 8. O Auditório do conservatório /9. A ex-Associação Trabalhista ferroviária hoje cinemateatro Boldin / 10. A inserção da arquitrave depois da demolição da alvenaria histórica para a realização do volume do palco / 11. O sistema dos alinhamentos nega a continuidade das estruturas de cobertura criando uma diferente possibilidade de relação entre espaços.

e arquitetônica de Carlo Savonuzzi, este se tornou o lugar para uma intervençáo que poderia ser definida como re-composiçãa $0^{14}$ arquitetônica, mais que de restauraçáo. Articulados ao longo de um novo cruzamento urbano definido pelas demoliçóes previstas pelo plano urbanístico iniciado em 1930, alguns edifícios públicos, projetados e construídos pelo próprio Savonuzzi a partir de 1935, formaram em uma década uma verdadeira "cidadela da cultura", a poucos passos do coraçấo da cidade histórica: a escola Alda Costa, o Museu de História Natural, a Escola de Música com a nova sala de concertos e a
Associação Trabalhista dos Ferroviários ${ }^{15}$ com a sala de cinema.

Uma intervenção de reconstrução urbana abrangente que inclui em um único processo de transformação o bloco do antigo hospital, reencontrando uma nova estrutura composta de ruas e espaços urbanos que envolve de forma hábil fragmentos de edifícios preexistentes. Savonuzzi preferiu mascarar o sedimento dos fragmentos dos edifícios remanescentes, renovando seu aspecto externo e interno, por meio da disposição de superfícies de revestimento em tijolo e pedra, molduras e cornijas 
em pedra natural e artificial, mantendo as relaçóes existentes entre espaços e volumes principais e secundários, estes últimos destinados a hospedar os serviços e os sistemas de conexão.

O projeto de Savonuzzi para a reutilização da primeira sala do hospital do século XV para acomodar a nova sala de concertos da Escola de Música, se insere em uma série de projetos de transformação de edifícios históricos em locais para espetáculos nos quais se podem encontrar alguns traços impressionantes da história da arquitetura, especialmente do século XX.

Do Teatro Farnese realizado no Palazzo della Pilotta em Parma de Giovan Battista Aleotti (1618) à sala de música no Altes Gewandhaus em Leipzig (1781) podem-se ver sinais de uma tradição que frequentemente usa a técnica composicional do duplo invólucro (conteúdo contemporâneo no contentor existente) para alocar espaços para a música, caracterizados por formas definidas por regras de acústica e representação cênica, dentro de espaços históricos, às vezes inadequados pelas relaçôes dimensionais e proporcionais.

Princípio na sequência retomado por Louis I. Kahn através da metáfora do violino (auditório e palco) e do estojo do violino (foyer e outros espaços de serviço para músicos e espectadores), utilizada para a composição de alguns projetos importantes e para a definição teórica de alguns princípios utilizados nos mesmos projetos (BROWNLEE e DE LONG, 2012; KAHN, 1972) ${ }^{16}$.

O Teatro Großes Schauspielhaus, em Berlim, resultante da transformação do circo Renz nos anos 1920, projetado por Hans Poelzig, é um dos exemplos dessa capacidade de conceber e realizar espaços de extraordinária complexidade figurativa e estratificação decorativa para funçôes tão específicas como àquelas ligadas ao espetáculo e à representação teatral.

Como exemplificado por alguns estudos (FORLANI, 1999), exemplos de reuso de espaços para o espetáculo são encontrados em diversos tipos de edifícios históricos com características muito diferentes entre si. Entre estes, no norte da Europa, alguns edifícios utilizados para circos equestres e para atividades esportivas cobertas provaram, por suas relaçóes dimensionais, ser adequados para sediar apresentações musicais e performances teatrais ${ }^{17}$.

Nos países localizados ao sul da Europa, no lugar dessas construçóes, igrejas e pátios no interior de edifícios e conventos são transformados em espaços que ocasionalmente hospedam espetáculos sagrados ou profanos.

Os edifícios industriais, devido à disposição repetida e à dimensão significativa das suas partes componentes, representam outros tipos de edifícios que se prestam facilmente a acolher formas especializadas, como aquelas ligadas à audiência e à representação ${ }^{18}$. Pelas mesmas razões que os edifícios industriais, os edifícios destinados a mercados e armazéns de mercadorias também oferecem oportunidades interessantes de reutilização deste tipo ${ }^{19}$.

O projeto de Carlo Savonuzzi para a reutilização do Primeiro Saláo do Hospital Sant'Anna, do século $\mathrm{XV}$, como sala de concertos da nova escola de música, situa-se nesta tradição de exemplos da história da arquitetura do século $\mathrm{XX}$, tanto pelo projeto urbano no qual se inscreve, como pelas peculiares características de invenção compositiva e de inovação técnica. Em primeiro lugar, pela forma extraordinariamente alongada do saláo do antigo hospital, inadequada para receber eventos musicais, exceto através de um sutil e cuidadoso trabalho de 
recomposição do invólucro interno que foi assim transformado em uma espécie de máquina telescópica que culmina no palco e em sua câmara acústica. Em segundo lugar pela experimentação de materiais inovadores para a época - como o isolante "acústico", composto de cal hidráulica e fibras de amianto - que conduziram, através da verificação em laboratórios especializados do Instituto Nacional de Eletrotécnica Galileo Ferraris de Turim, a um rendimento acústico ideal do salão. Um isolante "flexível" com diferentes características de absorção, em relação aos diferentes percentuais de amianto contido, a fim de obter um maior controle sobre a distribuição da energia sonora e, portanto, da recepçáo durante as apresentaçóes musicais.

A inovação das técnicas levou, em 2001, a um interessante e problemático paradoxo metodológico: a necessidade de se remover o amianto do saláo implicou no fechamento do espaço para o público (sem prejuízo às atividades didáticas internas

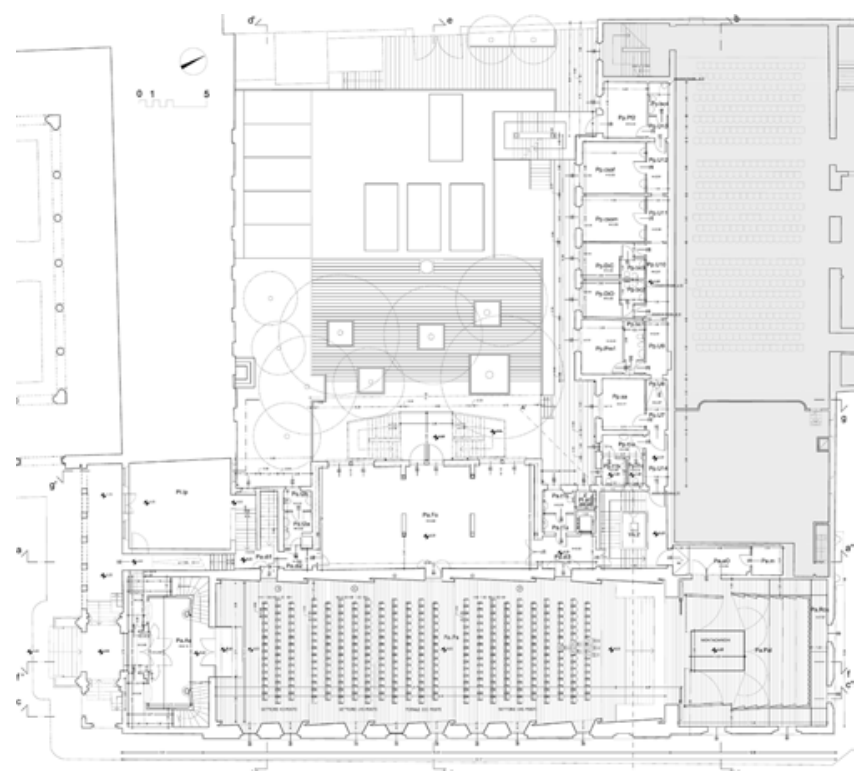

Fig. 8: Ferrara, Auditório no complexo do antigo Hospital Sant'Anna, planta baixa do projeto. ao Conservatório) e ao mesmo tempo tal fato evidenciou a dificuldade, se não a impraticabilidade de conservação do material original e, portanto, da forma proveniente do uso do material no invólucro interno da sala de concertos.

Em um contexto de tamanha importância, devolver a sala do auditório, fechada durante anos pela presença de amianto para o uso apropriado e de acordo com as normativas e requisitos atuais, imediatamente se mostrou uma tarefa complexa e fascinante para o grupo de pesquisa colocando à prova não apenas os conhecimentos individuais, mas principalmente a necessária interação e a possível integração entre as disciplinas envolvidas.

Olhando para o exemplo oferecido pela "cidadela da cultura", o projeto de restauração foi configurado como uma recomposição conjunta do salão e de outros espaços do auditório, o que significa que eles não ficariam necessariamente confinados à sala de

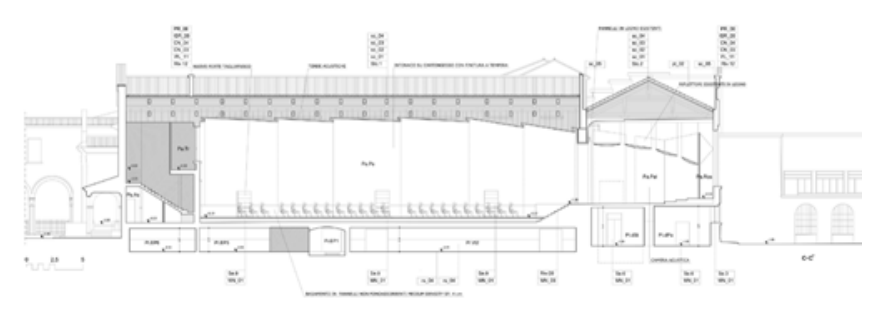

Fig. 9: Ferrara, Auditório no complexo do antigo Hospital Sant'Anna, corte longitudinal do projeto do salão principal, voltado para o pátio. 
concertos e ao palco, mas estendidos a outros espaços tais como: o de serviço do saláo, dos intérpretes, direção e gerência e dos serviços para o público.

Finalmente, o trabalho de pesquisa objetivou utilizar as técnicas de investigação mais avançadas para desenvolver um modelo cognitivo tridimensional da sala e de todo o complexo no qual está inserida, a fim de planejar a restauração da forma "existente", através do controle científico e da construção da sua "nova" forma, fazendo uso de materiais contemporâneos análogos aos originais, e de tecnologias relacionadas com os sistemas acústicos, de iluminação e de climatização.

\section{Projeto e conhecimento, projeto de conhecimento}

À luz das questôes do método e das experiências de pesquisa delineadas, faz-se necessário confrontar as disciplinas ligadas aos estudos históricos e aos bens culturais com as boas práticas relativas aos processos de requalificação e gestão dos bens arquitetônicos.

Os saberes que se articulam em torno do projeto arquitetônico e urbano poderiam obter um papel fundamental na definição dos objetivos de uma possível e desejável coordenação entre as diferentes contribuiçóes disciplinares.

A reduzida eficácia das políticas de tutela e proteção do patrimônio decorrem em grande parte, da dificuldade de diferenciar os graus de proteção dos bens e encarar com a necessária sistematização a questáo das formas de uso, desde a fase da definiçáo de valores e restrições e, portanto, da programaçáo subsequente da intervenção, mas, principalmente, por uma reflexão projetual sobre estes termos, que seja efetivamente capaz de gerar um amplo confronto com as demais disciplinas envolvidas.
Trata-se, de certo modo, de entrelaçar projeto e conhecimento, o momento investigativo com aquele estritamente projetual, considerando o projeto como instrumento de questionamento sobre as possíveis modalidades de conservação, restauro ou transformaçáo. Como uma ferramenta de pesquisa que permita avaliar as compatibilidades entre sistema arquitetônico original e os novos modos de uso hipotéticos.

Subverte-se assim a sequência na qual o projeto não importando a sua modalidade - é colocado como o último elo de uma cadeia de decisôes já tomadas, ou como uma impossível composição de assuntos indefinidos ou mal colocados - formas de uso, gestão, estratégias de comunicação - o que frequentemente resulta em implicaçôes operativas incongruentes com os valores histórico-documentais das preexistências.

Nesse sentido, o termo "conhecimento" é suscetível a diversos significados que vão desde a catalogação e levantamento do patrimônio, ao reconhecimento das fases de transformação da estrutura individual da edificaçáo e à leitura das potencialidades e vocaçóes compatibilizando novas formas de uso com as características e a história do edifício. A ponto de ser necessário pensar em um verdadeiro projeto de conhecimento, no qual as primeiras prefiguraçôes do trabalho permitam definir pressupostos úteis para orientar o estudo sobre os lugares e o levantamento dos dados, para que entáo possa ser influenciado pelo próprio conhecimento, em um procedimento não linear, mas que é expresso por aproximaçóes sucessivas. Trata-se na realidade um procedimento de "tentativa" no qual o conhecimento não desencadeia um método acumulativo, mas recursivo, já que o projeto é configurado como um paradigma dos 
valores envolvidos.

Independente desse entrelaçamento entre projeto e conhecimento, é possível delinear três possíveis estratégias no âmbito da valorização das preexistências e dos seus patrimônios arquitetônicos e culturais.

\section{Interdisciplinaridade}

Uma primeira estratégia necessária é fomentar o diálogo interdisciplinar em todas as fases projetuais e cognitivas que possam convergir para a requalificação do patrimônio existente.

É necessário gerar um embate de saberes através dos quais é possível ler e interpretar as diversas redes presentes no território. É necessário segundo Gambino (1998, p.37):

“[...] abordar o problema de como conceber as "redes de redes", como conceber, isto é, as inter-relaçôes, as interdependências $e$ as interferências entre as redes ecológicas (ou redes ambientais em um sentido mais amplo), redes históricas e culturais, assim como entre essas e as redes das cidades, as redes infra estruturais, as redes de comunicação, as redes de acesso.”

Redes que evidentemente remetem também a diversas técnicas de representação cartográfica e diferentes ferramentas de avaliação projetual relacionadas às oportunidades de planejamento e transformação do território. Técnicas e instrumentos que, por sua vez, pertencem a estatutos disciplinares e a teorias que, embora por vezes muito distantes entre si, devem estar necessariamente relacionados.
Além disso, é importante considerar que no âmbito do processo de atribuição de valor aos bens arquitetônicos, convergem saberes que normalmente não são considerados no campo da conservação dos bens culturais. Alguns historiadores e geógrafos consideram, por exemplo, que um edifício se transforma em patrimônio no momento em que se evidencia a transição de um circuito originário (especificamente de tipo produtivo no caso do patrimônio industrial) a um circuito semiótico (POMIAN, 1990, p.177-198): em outras palavras, o edifício desativado, ou no qual são menos evidentes os sinais das atividades originais, torna-se um contentor de significados (SODERSTROM, 1994, p.33).

\section{Transescalaridade}

Uma segunda estratégia é representada pela necessidade de atravessar as diversas escalas do projeto, considerando as relaçóes que mesmo os bens culturais isolados estabelecem com os sistemas materiais e imateriais que os contêm, capazes de estabelecer um horizonte cognitivo.

Esta capacidade de atravessar as diversas escalas foi aplicada, por exemplo, nos sistemas produtivos no âmbito dos palimpsestos territoriais (GABETTI e OLMO, 1985), explorando as interaçôes entre estruturas edilícias e territoriais no âmbito da arquitetura industrial, ou mesmo usando cartografias para ilustrar as transformaçóes, permanências e variaçóes nas preexistências relativas à cidade e ao território.

A “regiāo" como escala onde pode-se estudaro processo de industrialização, os fenômenos de descentralização geográfica das indústrias, as retículas sobrepostas e interceptantes das infraestruturas e dos serviços 
para a produção, o princípio de extraterritorialidade dos estabelecimentos produtivos definidos por limites, a higiene e o ambiente como representaçóes ideológicas que marcaram a construção da cidade industrial, são apenas alguns dos temas investigados nessas pesquisas.

As invariantes, as antigas e novas formas dos edifícios históricos no território são legíveis através de uma aproximação que só pode ser transescalar, de forma a detectar analogias e diferenças no âmbito dos edifícios singulares, dando a devida atenção para os laços que estes mantêm com os contextos socioeconômicos locais, mas também com as redes infra estruturais, que pela sua natureza, transcendem a escala do edifício e esclarecem com outros fatores, a dinâmica através da qual se desenvolveu a própria implantação.

\section{Multitemporalidade}

Uma terceira estratégia permite desenvolver a integração escalar e temporal de diferentes elementos presentes em áreas industriais desativadas através de oportunidades específicas, além de permitir experimentaçôes de processo e produto, promovendo uma imediata valorização das áreas através da coordenação de açóes de melhoria e uso, mesmo que temporárias, das áreas e dos edifícios. Devido à crise econômica global e do mercado imobiliário em particular, não se apresentam na verdade, condiçóes para intervir mediante planejamentos a médio e longo prazo.

Através da promoção de práticas inovadoras e o consequente desenvolvimento de uma complexa cadeia de regeneração, é possível explorar o enorme recurso imobiliário inutilizado, disponível como uma incubadora de empresas ao ar livre, para a formação de novos perfis profissionais especializados na cultura de reciclagem do tecido urbano existente.

Desta maneira, mediante açóes pontuais organizadas em fases temporais e integradas em um sistema de referência geral, é possível valorar áreas que, de outra forma teriam que ser objeto de investimentos massivos, incompatíveis com a atual crise de mercado, para que pudessem ser requalificadas em sua totalidade.

\section{Pluralidade}

Por fim, uma quarta estratégia é representada pelas experiências ligadas aos processos definidos pelo planejamento participativo, cujo o principal objetivo é identificar possíveis metodologias para a valorização e reativação de sítios industriais desativados ${ }^{20}$.

Em colaboração com a rede dos múltiplos stakeholders $^{21}$, é possível identificar alguns instrumentos essenciais - abordagem escalar, lógica de integração, estratégia incremental - e objetivos relacionados (MASSARENTE et al., 2017): encontrar um fio condutor, traçar um masterplan, fornecer um mapa das potencialidades.

Portanto, uma vez coletadas ideias e propostas provenientes dos parceiros envolvidos, podem-se iniciar as primeiras fases das oficinas participativas, para apresentar potencialidades, hipóteses de viabilidade e oportunidades regenerativas, levando em consideraçáo as ferramentas de planejamento e programação urbana vigentes ou previstos para a área, e individualizando diversos focos projetuais, tais como, "desenvolvimento", "reapropriação" e "conexão", em torno dos quais se constrói a ação concreta de regeneração da área. 


\section{Notas de fim:}

1. Nota do tradutor: do original Dinamiche di trasformazione della città. Metodi e politiche di valorizzazione dei Beni architettonici e ambientali.

2. Promovida pelo Departamento de Projetação Arquitetônico, pela Primeira Faculdade de Arquitetura da Politécnica de Turim e pela Sociedade de Engenheiros e Arquitetos de Turim, a Conferência foi realizada em Turim em maio de 2000.

3. Nota do tradutor: "Bigness é arquitetura extrema. Parece incrivel que o dimensionamento puro e simples de um edifício possa dar vida a um programa ideológico independente da vontade de seus projetistas." (KOOLHAAS, 1995b)

4. Nota do tradutor: do latim discrētus, particípio passado de discernere (discernir).

5. Nota do Tradutor: a Exposição Internacional de Construção de Berlim (em alemão: Internationale Bauausstellung Berlin, IBA Berlim) foi um projeto de renovação urbana iniciado em 1979 e concluído em 1987.

6. Nota do tradutor: grupo italiano formado em 1926 por Luigi Figini, Guido Frette, Sebastiano Larco, Giuseppe Pagano, Gino Pollini, Carlo Enrico Rava, Giuseppe Terragni e Ubaldo Castagnoli, sendo substituído posteriormente por Adalberto Libera. Pretendiam conjugar o racionalismo arquitetônico e o nacionalismo do Classicismo italiano com a logística estrutural do Futurismo.

7. Nota do tradutor: "come era dove era" é uma expressão que significa deixar as coisas como eram/são, sem modificar ou pretender novos usos. Esta expressão remete à reconstrução do Campanário da Basílica de San Marco em Veneza, após o seu completo desmoronamento em 14 de julho de 1902, com as mesmas formas (come era, como estava) e na mesma posição em que se encontrava (dove era, onde estava) antes da catástrofe.

8. Nota do tradutor: do original "teoria del caso per caso".

9. Nota do tradutor: do original "riuso".

10. Nota do tradutor: do original "il frequentato pensiero dell'uso". O autor se refere à passagem: "Architettura è scienza di molte discipline e di diversi ammaestramenti ornata, dal cui giudizio si approvano tutte le opere, che dalle altre arti compiutamente si fanno. Essa nasce da fabbrica e da discorso. Fabbrica è continuo ed esercitato pensiero dell'uso, che di qualunque materia, che per dar forma all'opera proposta si richiede, con le mani si compie. Fabbrica è continuo, ed esercitato, e come via trita, e battuta da passaggieri, frequentato pensiero d'indirizzare le cose a fine conveniente. Discorso è quello, che le cose fabbricate prontamente e con ragionevole proporzione può dimostrando manifestare." I dieci libri dell'architettura, Libro primo, de Vitruvio, traduzido e comentado por Daniele Barbaro, Venezia 1556.

11. Daniele Barbaro, historiador e tratadista, além de comitente de Palladio, traduziu e comentou De Architectura de Vitruvio Pollione em 1556.

12. Do qual o autor foi o responsável cientifico e coordenador do projeto arquitetônico.

13. Nota do Tradutor: Università degli Studi di Ferrara (Unife).

14. Nota do tradutor: do original: "re-composizione”

15. Nota do Tradutor: do original "Dopolavoro ferroviario"

16. Trata-se do projeto para o Fine Arts Center, School and Performing Arts Theater, Fort Wayne, Indiana, 195973.

17. Circo Municipal (1920) em Douai (França); Clube de tênis (Ballhof, século XVII) em Hannover (Alemanha).

18. Destilaria de malte (século XIX) em Snape (Inglaterra); Fábrica de automóveis Lingotto (1916-30) em Turim.

19. Armazém de trigo em Ivry (França); Mercado de peixe em Marselha (França); Bolsa de cereais em Blois (França); Arsenal militar (século XIX) em Metz (França).

20. O Tecnopólo da Universidade de Ferrara (TekneHub) definiu em 2016 um contrato de pesquisa com a REF Real Estate Ferrara, no qual seus pesquisadores, coordenados pelo autor, participam do processo de planejamento participativo coordenado pela KCity. O trajeto foi iniciado, entre 2009 e 2012, com a identificação da área como um local adequado para fazer parte do projeto europeu "ReTInA, Revitalisation of Traditional Industrial 
Areas", e através de uma aplicação inicial de metodologias para a regeneração da área, dividido em três macro fases: uma primeira na qual foi realizada uma análise do contexto, seguida da identificação de uma rede de stakeholders e, depois, de atividades de escuta e interação, que culminaram na realização de compromissos.

21. Nota do tradutor: pessoa ou grupo interessado em investimentos a partir de participação e risco.

\section{Referências Bibliográficas:}

ANNONI, A. Criteri e saggi per la conservazione e il restauro degli antichi edifici nel moderno rinnovamento delle città. In: Scienza ed arte del restauro architettonico, idee ed esempi. Milão: Framar, 1946.

BORSI, F; ROGGERO, M. Il patrimonio storico e il mondo moderno: aspetti italiani. In: Casabella. n. 314 , 1967.

BRANDOLINI, S. Tre ipotesi per le ceneri della Fenice. In: Lotus International. n. 103, 1999.

BROWNLEE, D.B.; DE LONG, D.G. Louis I. Kahn: In the Realm of Architecture. In: The Museum of Contemporary Art / Rizzoli. Los Angeles / Nova York: p. 346-351, 1991.

CONFORTO, C.; DE GIORNI, G.; MUNTONI, A.; PAZZAGLINI, M. Metodologie di intervento nel centro storico: Bologna, il diritto alla città. In: Il dibattito architettonico in Italia 1945-1975. Roma: Bulzoni, 1977.

DE CARLO, G. Urbino - la storia di una città e il piano della sua evoluzione urbanistica. Padova: Marsilio, 1966.

DE FUSCO, R. Alcuni contributi teorici. In: Dovera ma non comera. Il patrimonio architettonico e l'occupazione. Florença: Alinea, 1999.

FISCHER, A. Riuso. Esempi di nuova vita per vecchi edifici. Milāo: BE-MA, 1994.

FOCILLON, H. Vita delle forme. Torino: Einaudi, 1990.

FORLANI, M. C. (ed.) Spazi per lo spettacolo e riuso. Una ipotesi di attrezzatura territoriale. Roma: Gangemi, 1999.
FRANCO, C.; MASSARENTE, A.; TRISCIUOGLIO, M. (ed.) L'antico e il nuovo. Il rapporto tra città antica $e$ architettura contemporanea. Torino: Utet Università, 2002.

GABETTI, R. Progettazione architettonica e ricerca tecnico-scientifica nella costruzione della città. In: Imparare l'architettura. Scritti scelti sul sapere architettonico. Torino: Ed. Allemandi, 1997.

GABETTI, R.; OLMO, C. Discontinuità e ricorrenze nel paesaggio industriale italiano. In: Storia d'Italia. Annali 8. Insediamenti e territorio. Torino: Ed Einaudi, p.113-154, 1985.

GAMBINO, R. La valorizzazione del territorio storico. In: M. T. Maiullari Pontois. In: Ecomusei a rete e reti di ecomusei. Torino: 1998.

GRASSI, G. Progetti per la città antica. La mediocrità come scelta obbligata. In: Casabella. n. 666, 1999

KAHN, L. I. I Love Beginnings. In: Palestra "The Invisible City”, International Design Conference. Aspen. 19 Junho. 1972 .

KOOLHAAS, R. Bigness, ovvero il problema della Grande Dimensione. Macerata: Ed. Quodlibet, 2006.

Quodlibet, 2006.

he Generic City. Macerata: Ed.

MANIERI ELIA, M.Uso e modificazione. In: Restauro architettonico: il tema dell'uso. Ravenna: Ed. Edizioni Essegi-Comitato Giuseppe Giarola, 1990. 
MASSARENTE, A. (ed.) Conservazione, restauro, trasformazione: chi fa che cosa? In: Area. n. 32, 1997.

. (ed.) Ricomposizioni di uno spazio per

la musica. Studi per il restauro del complesso dell'auditorium nell'ex Arcispedale Sant'Anna a Ferrara. Quodlibet: Ed. Macerata, 2012.

. Fragments of antiquity in early Italian

Rationalism. Ed. A Esempi di Architettura. vol. 3, n. 2, p. 22-31, 2016.

. ; SUPPA, M.; VULLO, C. Alc.Este's

portrait. Knowledge, documentation, regeneration In: a brownfield case study. In: Le nuove frontiere del restauro. Trasferimenti, contaminazioni, ibridazioni. Veneza: Ed. Arcadia Ricerche S.r.l., p. 511-521, 2017.

MORIN, E. 1977, Il metodo: Ordine disordine organizzazione. Milão: Ed. Feltrinelli, 1992.

PASTOR, V. Introduzione. In Il Cantiere della Conoscenza, il Cantiere del Restauro. Bressanone: Ed. Atti del convegno, 1989.

PERRET, A. Le Musée Moderne. In: Mouseion. vol. 3, n. 9. 1929.

POMIAN, K. Musée et patrimoine. In: Patrimoine en folie, Maison des sciences de l'homme. Paris: Ed. Jeudy H.P., p. 177-198, 1990.

RIEGL, A. Il valore storico. In: Il culto moderno dei monumenti. Il suo carattere e i suoi inizi. Nuova Alfa: Ed. Bologna, 1903.

ROBERT, P. Ristrutturazioni. Nuovi usi per vecchi edifici. Milão: Ed.Techniche Nuove, 1990.

ROGGERO, M. F. Il museo dal taccuino dell'esperienza. Roma: Ed. Riuniti, 1999.

ROMA, G. Saper gestire i nuovi bisogni con l'architettura. In: l'Architetto, n. 141, 1999.

SECCHI, B. Edifici-mondo. Progetti per il centro storico di Salerno. In: Casabella. n. 667, 1999.

SODERSTROM, O. I beni culturali come risorse sociali di progetti territoriali. In: Beni culturali e geografia. Bologna: Ed. Patron, 1994. 